\title{
Thoracoscopic lymphadenectomy via multiportal approach: a narrative review
}

\author{
Yosuke Matsuura^, Kohei Hashimoto, Junji Ichinose, Masayuki Nakao, Mingyon Mun \\ Department of Thoracic Surgical Oncology, the Cancer Institute Hospital of Japanese Foundation for Cancer Research, Tokyo, Japan \\ Contributions: (I) Conception and design: Y Matsuura; (II) Administrative support: Y Matsuura; (III) Provision of study materials or patients: Y \\ Matsuura; (IV) Collection and assembly of data: Y Matsuura; (V) Data analysis and interpretation: Y Matsuura; (VI) Manuscript writing: All authors; \\ (VII) Final approval of the manuscript: All authors. \\ Correspondence to: Yosuke Matsuura, MD, PhD. Department of Thoracic Surgical Oncology, the Cancer Institute Hospital of Japanese Foundation for \\ Cancer Research, 3-8-31, Tokyo 135-8550, Japan. Email: yosuke.matsuura@jfcr.or.jp.
}

\begin{abstract}
Objective: This review article outlines the results and the actual technique of lymphadenectomy using video-assisted thoracoscopic surgery (VATS), with a particular focus on the multiportal approach.

Background: Lymphadenectomy plays an important role in the surgical treatment of lung cancer and is considered a cornerstone in assessing the stage and prognosis. Lymph node metastasis is an important factor in determining postoperative strategies and influences the outcome of cancer treatment. Nevertheless, there is no unanimous agreement on the role and technique of lymphadenectomy. Even the major societies of thoracic surgery and oncology have proposed different strategies, advice, and guidelines on this issue. The use of VATS for the treatment of lung cancer is increasing worldwide. Since the introduction of VATS, several studies have demonstrated that this minimally invasive approach is feasible, safe, oncologically efficient, and has several advantages over conventional open thoracotomy surgery, particularly for earlystage lung cancer. However, there is insufficient evidence for lymphadenectomy using a minimally invasive approach, which is often reported to be inferior to open thoracic surgery.

Methods: We reviewed a PubMed search for the latest relevant literature on lymphadenectomy for nonsmall cell lung cancer.

Conclusions: The goal of oncologic surgery is to ensure the longest possible survival rate. All these techniques have been extensively studied for long-term oncologic outcomes, including overall survival, disease-free survival, and recurrence rates. Future discussions of the "perfect lymphadenectomy" should focus more on other issues that have been discussed, such as the number of lymph nodes to be harvested, the most appropriate sites for analysis depending on the type of surgery and the location of the disease, and less on the comparison of the efficiency of different surgical approaches.
\end{abstract}

Keywords: Lung cancer; lymphadenectomy; video-assisted thoracoscopic surgery (VATS); multiportal approach

Received: 07 July 2021; Accepted: 13 August 2021; Published: 30 March 2022.

doi: 10.21037/asj-21-62

View this article at: https://dx.doi.org/10.21037/asj-21-62

\section{Introduction}

"Radical lobectomy," proposed by Cahan in 1960, emphasizes the importance of systematic dissection of the regional lymph nodes and is a procedure that is distinct from simple lobectomy (1). The regional lymph nodes refer to the interlobar, hilar, and mediastinal lymph nodes to which cancer cells could spread from the primary tumor; "lymphadenectomy" or "lymph node dissection" refers to

$\wedge$ ORCID: 0000-0003-3054-6760. 


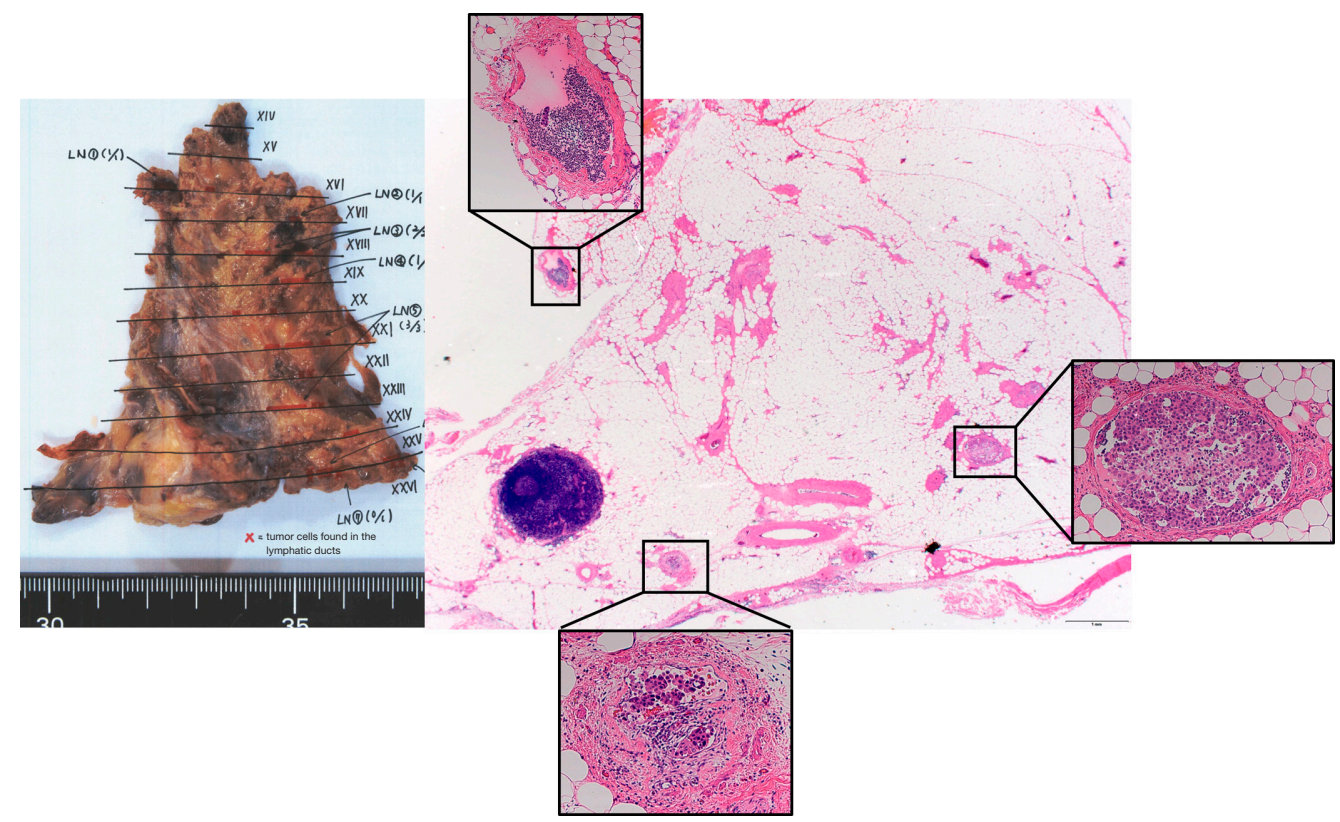

Figure 1 Dissected tissue as en bloc of the right upper mediastinum. Histopathologically, tumor clusters floating in the lymphatic duct are observed. LN, lymph node.

the procedure in which these lymph nodes are removed en bloc (2). Therefore, lymphadenectomy is an important therapeutic component in lung cancer surgery. However, there is still no consensus on the role and technique of lymphadenectomy. Even major societies of thoracic surgery and oncology have proposed different strategies, advice, and guidelines on this issue $(2,3)$.

Since the 1990s, video-assisted thoracoscopic surgery (VATS) lobectomy has become increasingly prevalent and is now a standard surgical approach instead of open thoracotomy (4). VATS has a better cosmetic appearance and faster postoperative recovery than open thoracotomy surgery (5). However, there is insufficient evidence regarding the oncological outcomes, especially for lymphadenectomy, for which it is often reported to be inferior to open thoracic surgery (6-8).

This review article outlines the results and the actual technique of lymphadenectomy by VATS, with a particular focus on the multiportal approach. We present the following article in accordance with the Narrative Review reporting checklist (available at https://asj.amegroups.com/ article/view/10.21037/asj-21-62/rc).

\section{Methods}

The latest relevant literature was searched in PubMed using the keywords: "lymphadenectomy," "lung cancer," and "VATS." The relevant studies in English were identified, screened, and reviewed by all the authors. Unpublished materials, congress abstracts, and proceedings were not selected. The authors are responsible for all aspects of the work to ensure that any questions relating to the accuracy or completeness of any part of the work are properly investigated and resolved.

\section{Definition of lymphadenectomy}

Lymphadenectomy is a procedure in which the lymph nodes to which cancer may have metastasized in an anatomically delineated area are completely removed en bloc with the surrounding lymphatic ducts and adipose tissue (2). Meanwhile, piecemeal resection of individual lymph nodes is defined as lymph node sampling, which can be distinguished from lymphadenectomy (2). There are some reports of a technique called "video-assisted mediastinoscopic lymphadenectomy (VAMLA)" (9); however, this technique is lymph node sampling using mediastinoscope, and the term "lymphadenectomy" should not be used. In cases where lymph node metastasis occurs, tumor cells are often found in the lymphatic ducts of the adipose tissue surrounding the lymph nodes (Figure 1). Lymphadenectomy is a more appropriate procedure for 
Table 1 Differences in the extent of mediastinal lymphadenectomy between systematic and selective lymphadenectomy in each guideline

\begin{tabular}{|c|c|c|c|c|c|c|}
\hline \multirow{2}{*}{ Guidelines } & \multicolumn{6}{|c|}{ Resected lobe } \\
\hline & Right upper lobe & Right middle lobe & Right lower lobe & Upper division & Lingular division & Left lower lobe \\
\hline \multicolumn{7}{|l|}{ Systematic } \\
\hline ESTS guideline & \multicolumn{3}{|c|}{$\# 2 \mathrm{R}, 4 \mathrm{R}, 7,8,9$} & \multicolumn{3}{|c|}{$\# 4 L, 5,6,7,8,9$} \\
\hline \multicolumn{7}{|l|}{ Selective } \\
\hline ESTS guideline & \multicolumn{2}{|c|}{$\# 2 \mathrm{R}, 4 \mathrm{R}, 7$} & $\# 4 \mathrm{R}, 7,8,9$ & \multicolumn{2}{|c|}{$\# 5,6,7$} & $\# 7,8,9$ \\
\hline Japanese ND2a-1 & \#2R, 4R & Not applicable* & $\# 7,8,9$ & \#4L, 5, 6 & Not applicable* & $\# 7,8,9$ \\
\hline
\end{tabular}

*, only for ND2a-2. ESTS, the European Society of Thoracic Surgeons.

lung cancer surgery compared to lymph node sampling.

\section{Types of lymphadenectomy}

Lymphadenectomy is classified according to the extent of dissection: (I) up to the hilum, (II) up to the ipsilateral mediastinum, and (III) up to the contralateral mediastinum and neck. Lymphadenectomy up to the ipsilateral mediastinum is the most common.

Ipsilateral mediastinal lymphadenectomy is also classified as follows: (I) systematic lymphadenectomy, which is a broad dissection from the superior mediastinum to the inferior mediastinum, and (II) selective lymphadenectomy (lobespecific lymphadenectomy). While the European Society of Thoracic Surgeons (ESTS) guidelines for systematic lymphadenectomy describe the ranges uniformly for the right and left sides, the Japanese guidelines omit dissection of \#8 and \#9 for tumors in the upper and middle lobes. In selective lymphadenectomy, only the superior mediastinal nodes $(\# 2 \mathrm{R}, 4 \mathrm{R}$ on the right side; \#4L, 5, and 6 on the left side) for upper lobe lung cancer and only the inferior mediastinal nodes $(\# 7,8,9)$ for lower lobe lung cancer are dissected in Japan, which is more limited than the ESTS guidelines $(2,10)$ (Table 1).

According to the International Association for the Study of Lung Cancer (IASLC) staging manual in thoracic oncology, the assessment of six nodes/nodal stations is recommended for proper nodal staging. Moreover, these should include three nodes/stations from the mediastinum, one of which should be subcarinal node \#7 and three nodes/stations from the hilum or other N1 locations (11). Therefore, systematic lymphadenectomy is considered the international standard. However, in recent North American clinical practice, it has been reported that in $83 \%$ of cases in which systematic lymphadenectomy was performed, the quality was equivalent to lymph node sampling. With the improvement of radiological technology, the trend is shifting from the era of uniform systematic lymphadenectomy to the era of selective lymphadenectomy according to each case. In Japan, a randomized phase III trial of lobe-specific $v s$. systematic lymphadenectomy for clinical stage I-II non-small cell lung cancer [Japan Clinical Oncology Group (JCOG) 1413] is currently ongoing (12). It will be interesting to determine if the scientific validity of selective lymph node dissection can be proven.

\section{Purpose of lymphadenectomy}

Lymphadenectomy plays an important role in the surgical treatment of lung cancer and is a cornerstone in assessing the stage and prognosis of this disease. The expected purpose of this procedure is as follows: (I) an accurate evaluation of the presence or absence of lymph node metastasis, which is beneficial for predicting the prognosis and for the indication of postoperative adjuvant therapy (staging effect), and (II) an improved prognosis by complete resection of metastatic lymph nodes (prognosis improvement effect) (2).

\section{Staging effect}

In the American College of Surgeons Oncology Group (ACOSOG) Z0030 trial (13), occult lymph node metastases (unsuspected $\mathrm{pN} 2$ ), which were not noted preoperatively or intraoperatively were identified in $4 \%$ of patients in the lymphadenectomy group when compared with the lymph node sampling group. Conversely, there was no increase 
in the complications, operative mortality, blood loss, or the length of hospital stay in the lymphadenectomy group, despite a 15 -minute increase in the operative time and a $121 \mathrm{~mL}$ increase in the total drainage volume, indicating that lymphadenectomy can be performed safely and contributes to a more accurate staging compared with the lymph node sampling group (14).

\section{Prognosis improvement effect}

Theoretically, an improved prognosis can be expected when there are lymph node metastases, and the metastases are confined to the dissected lymph nodes with little possibility of systemic dissemination (e.g., pN1, single pN2). Moreover, in the absence of lymph node metastasis (pN0), dissection is the same as resection of a cancer-free area, and there is no prognostic effect of dissection.

In the ACOSOG Z0030 trial, the median survival time in the lymph node sampling group was 8.1 years, compared with 8.5 years in the lymphadenectomy group (the median follow-up time was 6.5 years) (13). The lack of confirmatory evidence for a favorable effect of lymphadenectomy may be due to the following: (I) there was extensive systemic sampling in this study, (II) the majority of lung cancer surgery cases were pN0 cases, and (III) adjuvant chemotherapy was not standardized at the time of conducting this trial. However, scientific validation did not show that lymphadenectomy improved the prognosis.

Thus, although lymphadenectomy is considered the international standard, the established scientific evidence is in terms of staging efficacy, and its therapeutic significance has not been clarified.

\section{Lymphadenectomy by minimally invasive surgery}

The appropriate surgical approach for lymphadenectomy in lung cancer remains controversial. Several reports have described that the minimally invasive approach has a lower quality of lymphadenectomy than open thoracotomy (6-8). Meanwhile, no quality indicators of lymphadenectomy have been defined to date; there is still an open debate regarding the quality of nodal evaluation. The nodal upstaging rate and the total number of dissected lymph nodes may be quality indicators of lymphadenectomy $(6-8,15,16)$. However, the quality of lymphadenectomy should be assessed using long-term postoperative outcomes. The evaluation of postoperative recurrence patterns, especially at the site where lymphadenectomy was performed, is of paramount importance in assessing the quality of lymphadenectomy.

\section{Lymphadenectomy via multiport thoracoscopic approach}

\section{Comparison with open thoracotomy}

Several reports have indicated a higher rate of nodal upstaging after open thoracotomy than after multiportal VATS, suggesting that open thoracotomy could offer a more radical lymphadenectomy than multiportal VATS (6-8). However, we compared multiportal VATS and open thoracotomy, focusing on lymphadenectomy (17). The findings of this study are as follows: First, the effects of the surgical approach did not change the postoperative pathological nodal upstaging rate. Second, the prognoses were not significantly different between multiportal VATS and open thoracotomy. Finally, the recurrence patterns, including recurrences at the site where lymphadenectomy was performed, and post-recurrence overall survival rates between multiportal VATS and open thoracotomy were equal regardless of the pathological $\mathrm{N}$ status. Therefore, we confirmed that the quality of lymphadenectomy between multiportal VATS and open thoracotomy is equivalent when a highly experienced surgeon performs it, and several reports support this result (18-20).

\section{Comparison with other minimally invasive approaches}

A novel, minimally invasive approach, observed in robotic and uniportal surgeries, can assess an equal number of lymph nodes compared with open thoracotomy $(21,22)$. In addition, it has been reported that these approaches can remove more lymph nodes than multiportal VATS (21). Although both approaches are promising, there are few reports on the long-term oncological outcome, and there may be a bias in the surgical techniques among institutions; therefore, future studies are essential.

\section{Summary}

Regardless of the surgical approach, lymphadenectomy should be performed appropriately with the same quality and procedure. If adequate lymphadenectomy is performed, the rate of nodal upstaging and the number of dissected lymph nodes are expected to be the same. Accurate lymphadenectomy may simultaneously achieve accurate 

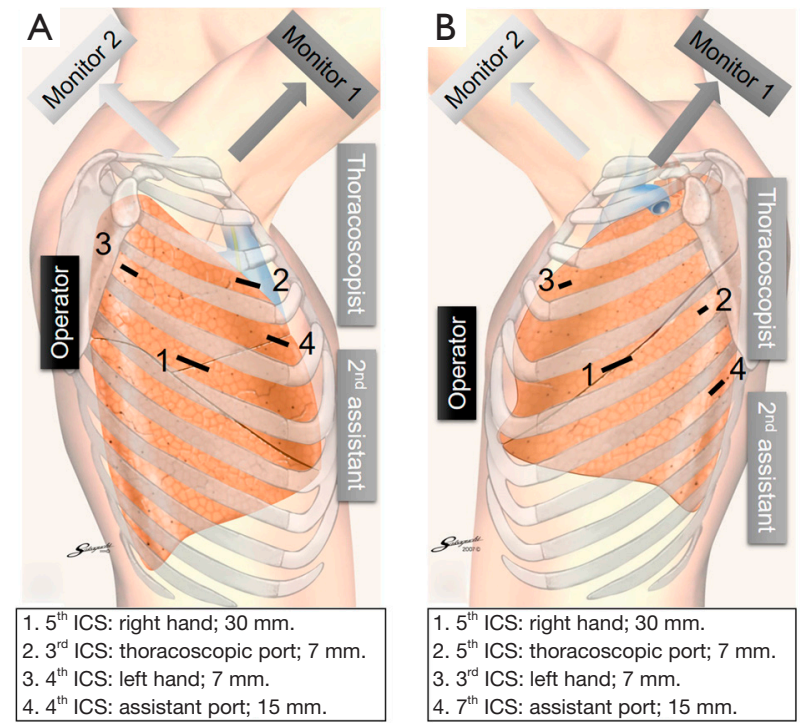

Figure 2 Port placement and confronting upside-down monitor setting (A) right side, (B) left side. Two monitors are set up on the cranial side of the patient, and the monitor for the assistants is placed upside down (Monitor 2). The surgeon stands on the right side of the patient for both right- and left-sided cases and looks at Monitor 1. The thoracoscopist and secondary assistants stand on the left side of the patient and look at Monitor 2. If the thoracoscopist keeps the thoracoscope in a horizontal position, mirror images and disorientation can be avoided. ICS, intercostal space.

lymph node staging and improve survival.

\section{Surgical techniques}

In this section, we have described the procedure of lymphadenectomy via multiportal VATS followed at our institute $(23,24)$.

\section{Principles of lymphadenectomy}

The procedure of lymphadenectomy requires the understanding of certain important principles, which are as follows, (I) ensuring a good surgical field and not performing surgery with poor vision, (II) achievement of anatomical landmarks, (III) avoiding direct grasping of lymph nodes, and (IV) ligation or clipping of the dissection edge.

\section{Port replacement}

At our institution, thoracoscopic lobectomy with systematic lymphadenectomy is performed via multiport (four ports: 7 , 7,15 , and $30 \mathrm{~mm}$ ) while routinely confronting an upsidedown monitor setting (Figure 2). Two monitors are set up on the cranial side of the patient, and the monitor for the assistants is placed upside down. The surgeon stands on the right side of the patient, and the thoracoscopic assistant and secondary assistant stand on the left side of the patient in all cases. During the operation, the secondary assistant provides the surgeon with a better view of the surgical site by placing two instruments using a $15 \mathrm{~mm}$ incision. The thoracoscopic assistant places a $7 \mathrm{~mm}$ port and can visualize all the structures in the chest cavity with a $5 \mathrm{~mm} 30^{\circ}$ rigid thoracoscope. For the surgeon, a $30 \mathrm{~mm}$ utility incision is made, and a $7 \mathrm{~mm}$ port is inserted for the surgeon's left hand. In this setting, the surgeon can freely use both hands and perform sharp dissection using scissors.

\section{Right mediastinal lymphadenectomy via four-port VATS}

In the case of right upper lobectomy, a $30 \mathrm{~mm}$ utility incision for the surgeon's right hand is made on the posterior axillary line in the $5^{\text {th }}$-intercostal space (ICS). A $15 \mathrm{~mm}$ incision for the secondary assistant is made on the anterior axillary line in the $4^{\text {th }}$-ICS. Two $7 \mathrm{~mm}$ ports are placed: one in the $3^{\text {rd }}$-ICS for the thoracoscope and one in the $3^{\text {rd }}$-ICS for the surgeon's left hand (Figure $2 A$ ). In the case of right middle or lower lobectomy, each port uses one ICS below.

\section{Subcarinal zone (\#7)}

The space between the upper and lower pulmonary veins is lifted. The right vagus nerve is identified. Subsequently, the \#7 lymph nodes are sequentially dissected from the pericardium and esophagus, and the left main bronchus is identified. The \#7 lymph nodes are dissected from the left and right main bronchi. Finally, the \#7 lymph nodes are clipped and divided from the top of the carina (Video 1).

\section{Upper zone (\#2R, \#4R)}

The pleura is incised at the anterior border of the vagus nerve to expose the entire length, and the distal side of the right brachiocephalic artery is identified. The anterior margin is dissected from the right lateral margin of the trachea. Subsequently, the pleura on the superior vena cava is incised, dorsal to the phrenic nerve. The pericardium at the cranial of the azygos vein is exposed, dissect upward, and the proximal side of the right brachiocephalic artery is identified. The thymus is divided and the tissue along 


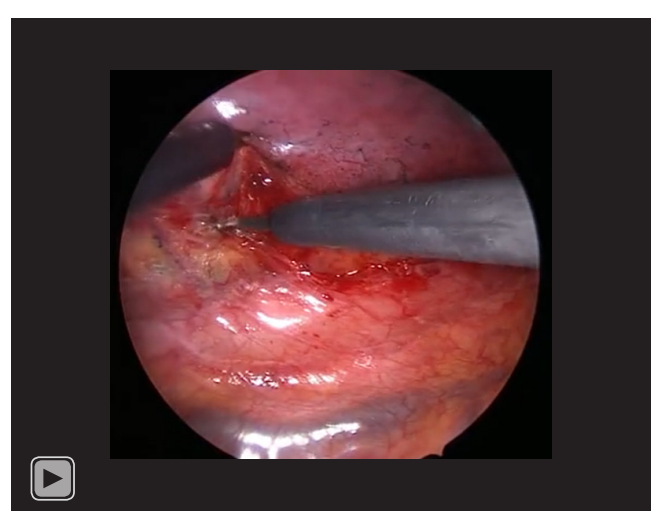

Video 1 Right subcarinal (\#7) lymphadenectom.

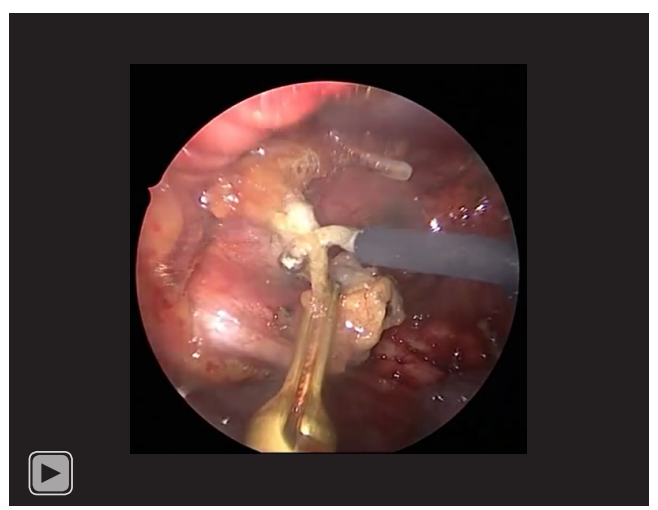

Video 2 Right upper and lower paratracheal (\#2R, 4R) lymphadenectomy.

the superior border of the right brachiocephalic artery is dissected, and the upper end of the dissection is determined. The lower end of the dissection is the main trunk of the pulmonary artery. Dissection is continued upward while clipping the left border of the trachea (Video 2).

\section{Left mediastinal lymphadenectomy via four-port VATS}

For left upper lobectomy, a $30 \mathrm{~mm}$ utility incision for the surgeon's right hand is made in the $5^{\text {th }}$-ICS. A $15 \mathrm{~mm}$ incision for the secondary assistant is made in the $7^{\text {th }}-\mathrm{ICS}$. Two $7 \mathrm{~mm}$ ports are placed: one in the $5^{\text {th }}$-ICS for the thoracoscope and one in the $3^{\text {rd }}$-ICS for the surgeon's left hand (Figure 2B). For left lower lobectomy, each port will be placed one ICS below as on the right side.

\section{Subcarinal zone (\#7)}

After the conventional hilar lymphadenectomy, we

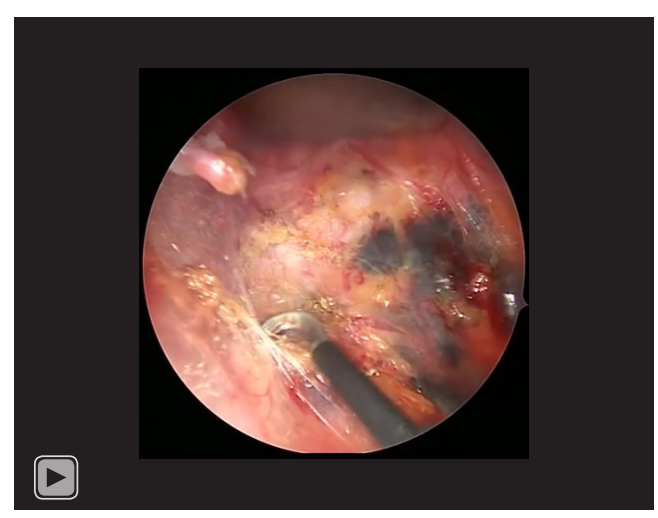

Video 3 Left subcarinal (\#7) lymphadenectomy.

lift the left main bronchus and stump of the left lower pulmonary vein using a thread and specially modified muscle retractor that may be inserted through a $15 \mathrm{~mm}$ incision. Consequently, the entire subcarinal area may be viewed posteriorly. Subsequently, the \#7 lymph nodes are sequentially dissected from the esophagus and pericardium. The right vagus nerve may be identified, followed by the right main bronchus. The \#7 lymph nodes are dissected from the right and left main bronchi. Finally, the \#7 lymph nodes are clipped and divided from the top of the carina (Video 3).

\section{Upper zone (\#4L) and AP zone (\#5, \#6)}

The secondary assistant retracts the lung anteriorly. The mediastinal pleura of the dorsal side is incised just in front of the aorta, and the bronchial arteries, directly branching from the aorta, are divided with a surgical energy device. The left main bronchus is dissected cranially using scissors. The vagus nerve is exposed, and the left recurrent laryngeal nerve is dissected distally. Dissection of the posterior area of the nodal packet, including the \#4L lymph nodes and surrounding structures, such as the left main bronchus, aortic arch, vagus nerve, and left recurrent laryngeal nerve, is completed before approaching the hilar structures. The \#4L lymphadenectomy is straightforward because the left recurrent laryngeal nerve has already been dissected, and only the anterior area of the \#4L remains to be dissected (Video 4).

\section{Major complications related to lymphadenectomy}

We reviewed 1,398 lung cancer patients who underwent radical lobectomy or more extensive pulmonary resection 


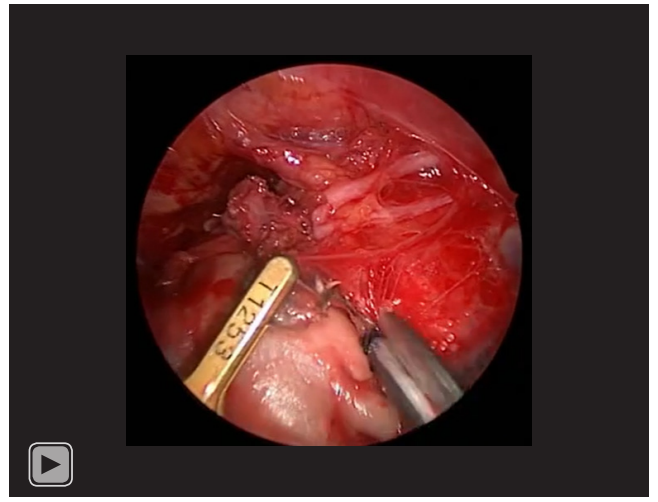

Video 4 Left lower paratracheal (\#4L), subaortic (\#5), and paraaortic (\#6) lymphadenectomy.

with mediastinal lymphadenectomy between 2010 and 2020 at our institute. Major postoperative complications related to lymphadenectomy were as follows: chylothorax in five, transient recurrent laryngeal nerve paralysis in 11 , and bronchopleural fistula in four patients; morbidity rate of $1.4 \%$. The results were considered to be acceptable.

\section{Conclusions}

The goal of oncologic surgery is to ensure the longest possible survival rate. All these techniques have been extensively studied in terms of long-term oncologic outcomes, including overall survival, disease-free survival, and recurrence rates. Future discussions of the "perfect lymphadenectomy" are required to focus more on other issues that have been discussed, such as the number of lymph nodes to be harvested, the most appropriate sites for analysis depending on the type of surgery and the location of the disease, and less on the comparison of the efficiency of different surgical approaches.

\section{Acknowledgments}

The authors sincerely thank Dr. Ken Nakagawa and Dr. Sakae Okumura for imparting their knowledge regarding the techniques of performing precise lymphadenectomy. The authors would also like to thank Editage (www.editage. com) for English language editing.

Funding: None.

\section{Footnote}

Provenance and Peer Review: This article was commissioned by the Guest Editor (Hitoshi Igai) for the series "Lymphadenectomy in Thoracoscopic Surgery" published in AME Surgical fournal. The article has undergone external peer review.

Reporting Checklist: The authors have completed the Narrative Review reporting checklist. Available at https:// asj.amegroups.com/article/view/10.21037/asj-21-62/rc

Peer Review File: Available at https://asj.amegroups.com/ article/view/10.21037/asj-21-62/prf

Conflicts of Interest: All authors have completed the ICMJE uniform disclosure form (available at https://asj.amegroups. com/article/view/10.21037/asj-21-62/coif). The series "Lymphadenectomy in Thoracoscopic Surgery" was commissioned by the editorial office without any funding or sponsorship. The authors have no other conflicts of interest to declare.

Ethical Statement: The authors are accountable for all aspects of the work in ensuring that questions related to the accuracy or integrity of any part of the work are appropriately investigated and resolved. All procedures performed in this study were in accordance with the Helsinki Declaration (as revised in 2013). The publication of this manuscript is waived from patient informed consent according to the ethics committee or institutional review board.

Open Access Statement: This is an Open Access article distributed in accordance with the Creative Commons Attribution-NonCommercial-NoDerivs 4.0 International License (CC BY-NC-ND 4.0), which permits the noncommercial replication and distribution of the article with the strict proviso that no changes or edits are made and the original work is properly cited (including links to both the formal publication through the relevant DOI and the license). See: https://creativecommons.org/licenses/by-nc-nd/4.0/.

\section{References}

1. CAHAN WG. Radical lobectomy. J Thorac Cardiovasc Surg 1960;39:555-72.

2. Lardinois D, De Leyn P, Van Schil P, et al. ESTS guidelines for intraoperative lymph node staging in non-small cell lung cancer. Eur J Cardiothorac Surg 2006;30:787-92. 
3. Rusch VW, Asamura H, Watanabe H, et al. The IASLC lung cancer staging project: a proposal for a new international lymph node map in the forthcoming seventh edition of the TNM classification for lung cancer. J Thorac Oncol 2009;4:568-77.

4. Lewis RJ, Sisler GE, Caccavale RJ. Imaged thoracic lobectomy: should it be done? Ann Thorac Surg 1992;54:80-3.

5. Bendixen M, Jørgensen OD, Kronborg C, et al. Postoperative pain and quality of life after lobectomy via video-assisted thoracoscopic surgery or anterolateral thoracotomy for early stage lung cancer: a randomised controlled trial. Lancet Oncol 2016;17:836-44.

6. Denlinger CE, Fernandez F, Meyers BF, et al. Lymph node evaluation in video-assisted thoracoscopic lobectomy versus lobectomy by thoracotomy. Ann Thorac Surg 2010;89:1730-5; discussion 1736.

7. Lee PC, Nasar A, Port JL, et al. Long-term survival after lobectomy for non-small cell lung cancer by video-assisted thoracic surgery versus thoracotomy. Ann Thorac Surg 2013;96:951-60; discussion 960-1.

8. Merritt RE, Hoang CD, Shrager JB. Lymph node evaluation achieved by open lobectomy compared with thoracoscopic lobectomy for N0 lung cancer. Ann Thorac Surg 2013;96:1171-7.

9. Hürtgen M, Friedel G, Toomes H, et al. Radical videoassisted mediastinoscopic lymphadenectomy (VAMLA)-technique and first results. Eur J Cardiothorac Surg 2002;21:348-51.

10. Hishida T, Miyaoka E, Yokoi K, et al. Lobe-Specific Nodal Dissection for Clinical Stage I and II NSCLC: Japanese Multi-Institutional Retrospective Study Using a Propensity Score Analysis. J Thorac Oncol 2016;11:1529-37.

11. Rami-Porta R, editor. International Association for the Study of Lung Cancer. Staging Manual in Thoracic Oncology. 2nd edition. North Fort Myers: Editorial Rx Press, 2016.

12. Hishida T, Saji H, Watanabe SI, et al. A randomized Phase III trial of lobe-specific vs. systematic nodal dissection for clinical Stage I-II non-small cell lung cancer (JCOG1413). Jpn J Clin Oncol 2018;48:190-4.

13. Darling GE, Allen MS, Decker PA, et al. Randomized trial of mediastinal lymph node sampling versus complete lymphadenectomy during pulmonary resection in the patient with N0 or N1 (less than hilar) non-small cell carcinoma: results of the American College of Surgery Oncology Group Z0030 Trial. J Thorac Cardiovasc Surg 2011;141:662-70.

14. Allen MS, Darling GE, Pechet TT, et al. Morbidity and mortality of major pulmonary resections in patients with early-stage lung cancer: initial results of the randomized, prospective ACOSOG Z0030 trial. Ann Thorac Surg 2006;81:1013-9; discussion 1019-20.

15. Ludwig MS, Goodman M, Miller DL, et al. Postoperative survival and the number of lymph nodes sampled during resection of node-negative non-small cell lung cancer. Chest 2005;128:1545-50.

16. Varlotto JM, Recht A, Nikolov M, et al. Extent of lymphadenectomy and outcome for patients with stage I nonsmall cell lung cancer. Cancer 2009;115:851-8.

17. Matsuura Y, Ichinose J, Nakao M, et al. Outcomes of nodal upstaging comparing video-assisted thoracoscopic surgery versus open thoracotomy for lung cancer. Lung Cancer 2021;152:78-85.

18. Licht PB, Jørgensen OD, Ladegaard L, et al. A national study of nodal upstaging after thoracoscopic versus open lobectomy for clinical stage I lung cancer. Ann Thorac Surg 2013;96:943-9; discussion 949-50.

19. Decaluwé H, Stanzi A, Dooms C, et al. Central tumour location should be considered when comparing N1 upstaging between thoracoscopic and open surgery for clinical stage I non-small-cell lung cancer. Eur J Cardiothorac Surg 2016;50:110-7.

20. Boada M, Guzmán R, Montesinos M, et al. UPSTAGING, CENTRALITY AND SURVIVAL IN EARLY STAGE NON-SMALL CELL LUNG CANCER VIDEOASSISTED SURGERY. Lung Cancer 2019;134:254-8.

21. Kneuertz PJ, Cheufou DH, D'Souza DM, et al. Propensity-score adjusted comparison of pathologic nodal upstaging by robotic, video-assisted thoracoscopic, and open lobectomy for non-small cell lung cancer. J Thorac Cardiovasc Surg 2019;158:1457-1466.e2.

22. Ismail M, Nachira D, Swierzy M, et al. Lymph node upstaging for non-small cell lung cancer after uniportal video-assisted thoracoscopy. J Thorac Dis 2018;10:S3648-54.

23. Mun M, Ichinose J, Matsuura Y, et al. Video-assisted thoracoscopic surgery lobectomy via confronting upsidedown monitor setting. J Vis Surg 2017;3:129.

24. Ichinose J, Matsuura Y, Nakao M, et al. A novel procedure of thoracoscopic 4L lymph node dissection: 4L posterior first technique. J Vis Surg 2020;6:11.

doi: 10.21037/asj-21-62

Cite this article as: Matsuura Y, Hashimoto K, Ichinose J, Nakao M, Mun M. Thoracoscopic lymphadenectomy via multiportal approach: a narrative review. AME Surg J 2022;2:3. 